\title{
Marfan's syndrome presenting as bilateral spontaneous pneumothorax
}

\author{
DAVID J. GAWKRODGER \\ M.B., Ch.B., M.R.C.P. \\ Department of Medicine, City General Hospital, Stoke on Trent ST4 6QG
}

\begin{abstract}
Summary
A case of bilateral spontaneous pneumothorax in a 14-year-old girl with previously undiagnosed Marfan's syndrome is described. The pulmonary abnormalities of Marfan's syndrome are not commonly encountered and bilateral pneumothorax is itself a rare event which, in most instances, has been reported following invasive procedures.
\end{abstract}

\section{Case report}

A 14-year-old schoolgirl presented with a 12-hr history of tightness in her chest and shortness of breath. Over the preceding 2 weeks she had noticed a clicking coming from the left side of her chest but had otherwise been well and had not been breathless. At presentation she was too dyspnoeic to talk and breath sounds were reduced in all areas of the chest. Bilateral pneumothorax was confirmed by the chest radiograph, and intercostal underwater seal drainage tubes were inserted at both apices with relief of symptoms (Fig. 1). Subsequently the right lung re-expanded fully but there was a persisting pneumothorax on the left despite repositioning of the drainage tube. At thoracotomy 6 weeks later, the apex of the left lung had a granular appearance but no bullae were noted. She underwent left pleurectomy and has been well since. The patient exhibits many of the skeletal manifestations of Marfan's syndrome. Her height was $180 \mathrm{~cm}$ with an arm span of $200 \mathrm{~cm}$. The crown-pubis to pubis-sole ratio was 0.843 (normal value of 0.931 ; McKusick, 1972). She had a metacarpal index within the range for Marfan's syndrome at $10 \cdot 1$ (Sinclair, Kitchin and Turner, 1960). A high arched palate was evident, with arachnoidactyly and hyperextensible joints. Both the wrist sign and thumb sign were positive (McKusick, 1972). There was no evidence of heart disease and ectopia lentis was not demonstrated on slit lamp examination, but she had myopia. Urine electrophoresis showed no excess of homocysteine and pulmonary function tests (performed after pleurectomy) were normal. There was no family history of Marfan's syndrome.

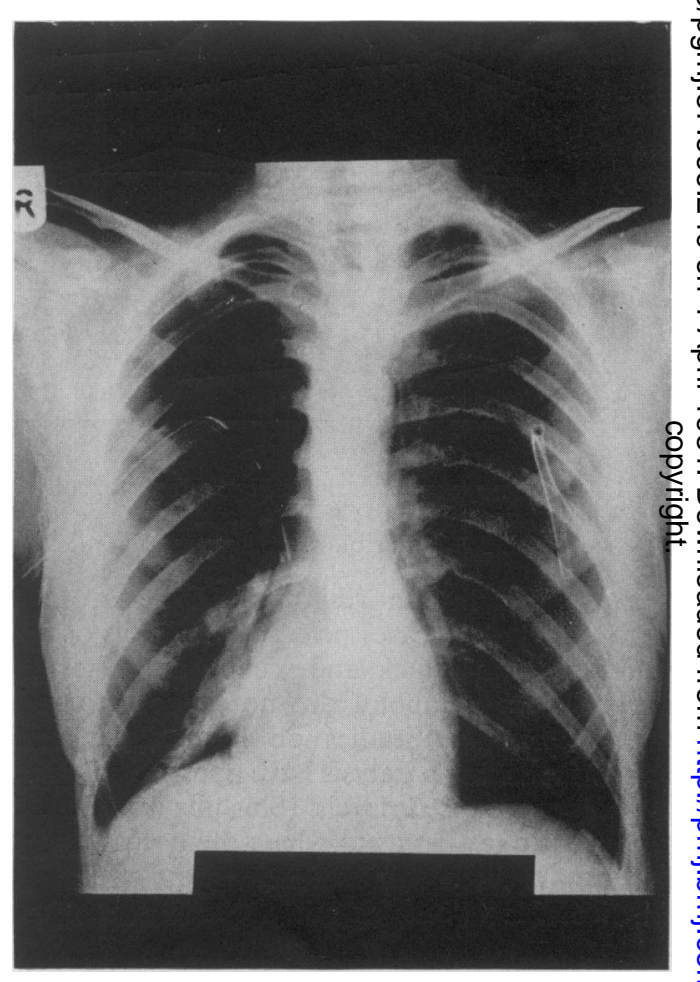

FIG. 1. Chest radiograph showing bilateral pneumothoraces응 (taken immediately after the insertion of apical intercostal drainage tubes).

Discussion

Bilateral pneumothorax is an uncommon event and 0 N most reported cases have followed invasive pro- $\omega$ cedures such as tracheostomy (Parikh, 1965), mediastinoscopy (Furgang and Saidman, 1972), and subclavian or jugular vein catheterization (Maggs and Schwaber, 1977; Arnold, Feathers and Gibbs, + 1973). It has also been described after the induction $\frac{7}{0}$ of anaesthesia in patients with chronic obstructive $\underset{\mathbb{D}}{\stackrel{D}{*}}$

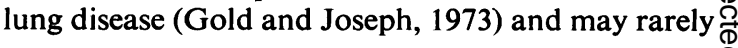


complicate pulmonary metastases (Singh, Singh and Kaur, 1977), or result from traumatic injury to the bony thorax (Jones, 1974).

Bilateral spontaneous pneumothorax has not hitherto been described in Marfan's syndrome although unilateral spontaneous pneumothorax is recorded (McKusick, 1972) together with other pulmonary abnormalities, which include diffuse and bullous emphysema (Turner and Stanley, 1976), congenital malformations (Dwyer and Troncale, 1965), bronchiectasis (Teoh, 1977) and honeycomb lung (Lipton, Greenwald and Seriff, 1971). Some of the reported cases of spontaneous pneumothorax in Marfan's syndrome have had radiologically obvious underlying lung abnormalities such as emphysematous bullae (Turner and Stanley, 1976) or honeycomb lung (Lipton et al., 1971), but the majority of patients, including the present case, do not have any pulmonary abnormality to account for the spontaneous pneumothorax.

No microscopic or molecular abnormality of collagen or elastin has yet been demonstrated in Marfan's syndrome (Lamberg, 1978), although a post-mortem study on infants with the syndrome did show thickened and fragmented elastic fibres in the alveolar sacs of areas affected by pulmonary emphysema (Reye and Bale, 1973). Similar changes are observed in the elastic lamina of large arteries in Marfan's syndrome, supporting the concept of a connective tissue abnormality predominantly affecting elastic fibres. Recently an abnormal granular material attached to the elastic tissue microfibrils and staining as glycosaminoglycan has been demonstrated by electronmicroscopy in fibroblasts cultured from patients with Marfan's syndrome (Lamberg, 1978). This observation suggests a fault in glycosaminoglycan control as being the underlying connective tissue defect.

The coincidence of the 2 rare clinical conditions described in the present case suggests the possibility that increased fragility of pulmonary connective tissue is responsible for spontaneous pneumothorax in Marfan's syndrome.

\section{Acknowledgments}

I thank Dr R. B. Cole for his kind advice and am grateful to $\mathrm{Mr} \mathrm{W}$. G. Coddington for performing the ophthalmological examination.

\section{References}

Arnold, S., Feathers, R.S. \& GibBs, E. (1973) Bilateral pneumothoraces and subcutaneous emphysema. A complication of internal jugular venepuncture. British Medical Journal, 1, 211.

DWyer, E.M. \& Troncale, F. (1965) Spontaneous pneumothorax and pulmonary disease in the Marfan syndrome. Annals of Internal Medicine, 62, 1285.

Furgang, F.A. \& Saidman, L.J. (1972) Bilateral tension pneumothorax associated with mediastinoscopy. Journal of Thoracic and Cardiovascular Surgery, 63, 329.

GolD, M.I. \& JoSEPH, S.I. (1973) Bilateral tension pneumothorax following induction of anaesthesia in 2 patients with chronic obstructive airways disease. Anaesthesiology, 38, 93.

LAMBERG, S.I. (1978) Stimulating effect of exogenous hyaluronic acid distinguishes cultured fibroblasts of Marfan's disease from controls. Journal of Investigative Dermatology, 71, 391.

Lipton, R.A., Greenwald, R.A. \& Seriff, N.S. (1971) Pneumothorax and bilateral honeycombed lung in Marfan's syndrome. American Review of Respiratory Disease, 104, 924.

JONES, D. (1974) Bilateral fracture of the first rib with bilateral pneumothorax. Injury, 5, 255.

McKusick, V.A. (1972) Heritable Disorders of Connective Tissue 4th Edn, p. 61. C. V. Mosby, Saint Louis.

Maggs, P.R. \& Schwaber, J.R. (1977) Fatal bilateral pneumothoraces complicating subclavian vein catheterization. Chest, 71, 552.

PARIKH, S.D. (1965) A case of bilateral pneumothorax after tracheostomy. Journal of Laryngology and Otology, 79, 457.

Reye, K.D.K. \& Bale, P.M. (1973) Elastic tissue in pulmonary emphysema in Marfan syndrome. Archives of Pathology, 96, 427.

Sinclair, R.J.G., Kitchin, A.H. \& Turner, R.W.D. (1960) The Marfan syndrome. Quarterly Journal of Medicine, 113, 19.

Singh, H., Singh, N. \& KaUR, R. (1977) Bilateral spontaneous pneumothorax with pulmonary metastases from synovial cell sarcoma. British Journal of Diseases of the Chest, 75, 211.

Tеон, P.C. (1977) Bronchiectasis and spontaneous pneumothorax in Marfan's syndrome. Chest, 72, 672.

Turner, J.A.McM. \& Stanley, N.N. (1976) Fragile lung in the Marfan syndrome. Thorax, 31, 771. 